\title{
Economic well-being and British regions: the problem with GDP per capita
}

\author{
David Harvie, Bruce Philp, Gary Slater and Dan Wheatley
}

August 2007

\begin{abstract}
Economists and policy-makers often present per capita GDP as by far the most significant indicator of economic well-being. Such measures are frequently adopted in making international comparisons, constructing time-series for particular countries and in studies of regional inequality. In this paper we challenge this view using a regional analysis of 2001 data focusing upon differences between London and the south-eastern regions, in comparison to the rest of Great Britain (GB). Initially GDP per capita is decomposed into the demographic and labour-market factors which generate it. Thereafter we broaden the notion of work-time used in productivity measures to include other necessary work-related activity, namely commuting. This leads to us to construct a new indicator which we call social productivity. Our conclusion is that our decomposition and notion of social productivity are both relevant in comparisons of regional well-being; in addition such methods may be used fruitfully in international and historical contexts.
\end{abstract}

JEL classification: B50, I31, R23

Keywords: Welfare; GDP; Commuting; Productivity; Regional analysis

\section{Acknowledgments}

The authors would like to thank participants at the April 2007 Regional Studies Association Conference, Lisbon, for comments on an earlier draft. The authors also acknowledge ESRC grant number PTA-030-2005-00807 in supporting this research.

\section{Author Affiliations}

David Harvie: University of Leicester School of Management; Bruce Philp: Nottingham Trent University; Gary Slater: University of Bradford; Dan Wheatley: Nottingham Trent University. 


\section{Introduction}

Gross Domestic Product (GDP) is considered by most economists and policy-makers to be the principal indicator of a nation or region's wealth. Concomitantly, GDP per capita is the most important measure of individual economic welfare. Thus, high levels of, and steady growth in, both GDP and per capita GDP are primary aims of economic policy. Such an emphasis is common to supranational institutions such as the World Bank, which prescribes policies for economic development, political bodies such as the European Union, as well as national and regional governments setting policy goals at both these levels. For example, recent UK government studies (e.g. HM Treasury, 2001) begin with a regional GDP per capita measure of economic welfare.

But GDP per capita does not take into account other elements which are important in explaining well-being, and a number of thinkers have begun to challenge the dominance of this measure, pointing out its inadequacies and proposing alternatives. Probably the best-known alternative is the Human Development Index (HDI), which combines GDP per capita with two other indicators - literacy and average life expectancy — into a single index. The United Nations' Human Development Report, published annually, includes a ranking of countries’ HDI indices. In this index, GDP per capita is used to measure 'command over resources'. Osberg and Sharp (2005) have recently proposed an alternative, broader concept of 'command over resources', taking account of factors such as working time, the real value of unpaid labour, and poverty intensity. They go on to construct their Index of Economic Well-Being (IEWB) for a number of industrialised countries, including the US, the UK, and Germany. Clarke and Islam (2003) also take into account various factors that diminish welfare (commuting, corruption, pollution and so on): on this basis they calculate a 
cost-benefit adjusted measure of per capita GDP for Thailand. This work is valuable, but one criticism might be that they assume that a variety of disparate factors which contribute negatively or positively to well-being can be reduced to a single monetary measure.

In making international (and regional) comparisons it is also important to distinguish per capita income from productivity, since the effect of variations in working hours are ignored by the former. In comparing a number of leading economies Maddison (1995) identifies interesting trends, with remarkable achievements being made in GDP per capita by a number of East Asian economies in the period 1950-1992. In this context Crafts (1997) has directly identified the role of differences in working hours, which can be very varied between countries with similar levels of GDP per capita. To overcome this problem Crafts (1997) suggests that a GDP per hour worked (or productivity) measure of economic welfare may be more appropriate and, moreover, that claims for the success of areas such as East Asia should be tempered against the backdrop of long-hours cultures.

This insight raises interesting questions that relate to our regional study of England, Wales and Scotland. In the first substantive part of the paper (section 2), we argue that an exclusive focus on GDP per capita may give a misleading picture of the relative success of British regions, in particular the apparent success of London, the East and South East. For example, we find that in the case of Londoners, high levels of GDP per capita are due, mainly, to high productivity levels. But Londoners’ per capita GDP is also inflated by longer than average working hours. With contemporary interest in issues of work-life balance, this realisation is pertinent since there has been a preoccupation, in government regional policy, with such variables as average output 
and average productivity. Other labour-market conditions have implications for welfare too. In London higher than average labour-force participation exerts a positive influence on per capita GDP, but the effect of employment is negative with residencebased unemployment higher than the British average. So, while London appears to do well if we consider a simple GDP per capita measure of well-being, when we look more closely, decomposing data to demonstrate how labour market conditions generate relatively high income levels, the regional performance of London is less impressive. Londoners, on average, work long hours, are more likely to work beyond retirement age, are more likely to be unemployed, and may work more intensively than other workers in Britain.

In the paper's second substantive part (section 3) we further interrogate the categories used to measure well-being in GB regions, suggesting how the former could be developed to better reflect welfare levels. Some classical economists were interested in value categories and this relates in particular to labour-time. Adam Smith, for instance, considered how the 'necessaries and conveniences of life' were produced and distributed (1970, p.104); for him, the real cost of things was the 'toil and trouble' of acquiring them (p.133). As we note in this paper, a GDP per capita measure of well-being, in contrast to a productivity measure, does not capture the extent of this 'toil and trouble'. Marxian value analysis too considers the labour-time taken to produce commodities, and it is in this setting that Marx locates his theory of exploitation. In fact, Marx is concerned with socially necessary labour time, that is, 'the labour-time required to produce any use-value under the conditions of production normal for a given society and with the average degree of skill and intensity of labour prevalent in that society’ (Marx, 1979, p.129). For Marx, ‘[w]hat exclusively determines the magnitude of the value of any article is therefore the amount of labour 
socially necessary, or the labour-time socially necessary for its production’ (p.129). Perhaps, then, value reasoning may offer an alternative starting point for regional accounting. A problem, however, for Marxian approaches, concerns the question of what exactly should be counted as part of 'socially necessary' labour time. This question has become even more pertinent given shifts in the nature of work over the past few decades, particularly in the global North, with the increasing importance of so-called 'immaterial' labour (Lazzarato, 1996) blurring the distinction between work time and non-work time (e.g. Hardt and Negri, 2000).

A full exploration of all the issues raised by these trends is well beyond the scope of this paper. However, we do identify one particular activity, namely commuting, which can be measured. As we argue in section 3, for most employees a non-trivial portion of each working day is taken up with the journey to and from their workplace. Such time is not usually counted as part the working day — and a private employer would certainly not consider it as such. Yet such minutes or hours are not part of leisure time, since they are foregone in work-related activity. In fact, this time may be as 'socially necessary' to production as activity performed in the 'workplace' itself. Thus, for both mainstream and radical approaches, commuting time should be considered a cost both to the individual employee and to society. We suggest the labour-leisure dichotomy employed in the standard account of labour supply, and the notion of socially necessary labour time employed by Marx, both neglect the necessary nature of time spent in work related activity, such as commuting. Instead we propose an alternative measure of productivity which reflects more fully the 'toil and trouble' of producing goods and services and, hence, is a more appropriate indicator of well-being than those presently used in regional studies. We call this measure social productivity. Ideally it should include a number of work-related 
activities, for example, getting ready for work, personal grooming, thinking about and planning work tasks outside of work time. However, in our attempt to operationalise this variable, we focus only on commuting because data sets provide information on this activity, clearly separated from household activities. ${ }^{1}$

\footnotetext{
${ }^{1}$ The very fact that many activities cannot be obviously categorised as 'work' or 'leisure' has led theorists such as Negri to use language such as ‘blurring’ and to suggest that value production now takes place 'outside any economic measure’ (Negri, 1994, p. 28; authors’ translation). Does one shave every morning or apply make-up for oneself or for one’s employer? Is the camaraderie created through after-work drinking mere socialising or does it also engender more productive cooperation during working hours?
} 


\section{Per capita GDP, productivity and regional well-being}

\subsection{Decomposing Per Capita GDP}

The election of the Labour Government in 1997 provided a new impetus for regional policy and decision-making. While the latter may have been unfulfilled, regional accounts are still a focus for policymakers, with recent government analyses of British regions using a per capita GDP measure of economic well-being, consistent with claims by both national governments and the European Union that high levels of, and steady growth in, GDP per capita, are primary aims of national and regional policy. High levels of employment and productivity growth (conceived of in this context as average income per hour worked) are also seen as desirable objectives. ${ }^{2}$ Against this backdrop, we feel our investigation of GDP per capita, productivity and various labour market indicators is important. In this paper we aim to challenge the basis for the main measures of regional well-being - GDP per capita and a conventional productivity measure — by expanding these measures (via decomposition) to explicitly look at the effects of variations in participation, working hours and unemployment. In section 3 we will expand our criticism, reconsidering the 'hours worked' denominator in UK Government productivity measures. Our intention is to offer an alternative, more radical way to assess the success of different regions.

Our claim is predicated on the view that the indictors used to make regional comparisons — such as growth in GDP per capita and GDP per hour worked — fall into the trap of equating commodity production with well-being, and abstract from the

\footnotetext{
${ }^{2}$ In recent decades it has been perceived that there is an unemployment problem across the EU and it is also acknowledged that regional differences in joblessness are ‘considerable’ (Martin, 1998, p.18).
} 
conditions under which production occurs. This criticism has been well summarised by Benneworth et al who have argued that,

It is much easier to conceptualise both the UK government's understanding of regions and why they have in reality become increasingly important through explaining the curious way in which 'regions' and regional institutions have become seen almost exclusively in some circles as a mechanism for promoting innovation, and hence pursuing a particular kind of neoliberal agenda. (2006, p.5).

We maintain a clear connection has to be made between the average incomes, and the conditions under which those incomes are generated. What we wish to argue is that focusing on a GDP per capita measure of well-being only acknowledges our wellbeing as consumers, and ignores it as producers. ${ }^{3}$

In order to illuminate these issues we will outline how per capita GDP can be decomposed into a number of constituent parts, before discussing the results of performing such a decomposition for the regions of Great Britain. While varying levels of productivity are key in driving differences in per capita GDP, as the analysis

\footnotetext{
${ }^{3}$ One legitimate complaint which might be directed towards our paper is that it itself focuses too narrowly on the economic aspects of regional difference, and we ignore more general social patterns. As noted by Harvey: 'There are processes at work ... that define regional spaces within which production and consumption, supply and demand (for commodities and labour power), class struggle and accumulation, culture and life style, hang together as some kind of structured coherence within a totality of productive forces and social relations.' (Harvey, 1985, p.146)
} 
below indicates, similar productivity levels can translate into very different outcomes in terms of GDP per capita, due to labour market and demographic factors. ${ }^{4}$

We explore the sources of differential levels of per capita output by making a series of decompositions that link this variable with hourly productivity (average income per hour worked in a region), working hours, employment and participation rates, and demographic variables. First, per capita output, $Y / P$, for region $i$ can be written as the product of average hourly output or productivity, $\mathrm{Y} / \mathrm{H}$, and average hourly labour input per person, $H / P$ :

$$
(Y / P)_{i}=(Y / H)_{i} \cdot(H / P)_{i}
$$

Second, average per capita working hours can be decomposed into: average hours worked per person employed, $H / E$; employment relative to the total labour force, $E / L$; the ratio of the labour force to the 'adult' population (persons aged 16 or over), $L / P_{\mathrm{A}}$; and the share of the adult population in the total population, $P_{\mathrm{A}} / P$ :

(2) $\quad(H / P)_{i}=(H / E)_{i} \cdot(E / L)_{i} \cdot\left(L / P_{\mathrm{A}}\right)_{i} \cdot\left(P_{\mathrm{A}} / P\right)_{i}$.

Thus, combining (1) and (2), we can write:

$$
(Y / P)_{i}=(Y / H)_{i} \cdot(H / E)_{i} \cdot(E / L)_{i} \cdot\left(L / P_{\mathrm{A}}\right)_{i \cdot} \cdot\left(P_{\mathrm{A}} / P\right)_{i} .
$$

Alternatively, we can rewrite (3) as

(3a) $\quad(Y / P)_{i}=52 \cdot y_{i} \cdot h_{i} \cdot e_{i} \cdot p_{i} \cdot d_{i}$,

where $y_{i}=(Y / H)_{i}, h_{i}=(H / E)_{i} / 52$ (average weekly working hours for employed persons), $e_{i}=(E / L)_{i}, p_{i}=\left(L / P_{\mathrm{A}}\right)_{i}$, and $d_{i}=\left(P_{\mathrm{A}} / P\right)_{i}$.

\footnotetext{
${ }^{4}$ van Ark and McGuckin (1999) undertake a similar analysis on a cross-national basis
} 
Finally, we can decompose the last three components — employment rate, participation rate, and the demographic variable — according to whether a person is of 'working age', W (from 16 to 59/64 years of age inclusive) or of usual 'retirement age', R (60 years or older for women and 65 years or older for men). We thus obtain:

$$
(Y / P)_{i}=52 \cdot y_{i} \cdot h_{i} \cdot\left[e_{\mathrm{W} i} \cdot p_{\mathrm{W} i} \cdot d_{\mathrm{W} i}+e_{\mathrm{Ri}} \cdot p_{\mathrm{R} i} \cdot d_{\mathrm{R} i}\right]
$$

where $e_{j i}$ is the employment rate for those in age-group $j, p_{j i}$ is the participation rate for those in age-group $j$, and $d_{i j}$ is the share of those in age-group $j$ of the total population. ${ }^{5}$

To undertake this decomposition labour market and demographic data are required, together with an appropriate measure of output. The former are taken from the British Labour Force Survey (LFS), a quarterly household survey containing information on approximately 150,000 individuals. From this, it is possible to identify numbers employed (both dependent and self-employed), the economically active population and the total population by age class within each region. The LFS also includes detailed information on hours worked. Questions are asked concerning usual and actual hours of work in both main and second jobs, including any overtime working, whether paid or not. The estimates in Table 1 below are derived from actual hours worked in main and second jobs, including any overtime, during the week of the

\footnotetext{
${ }^{5}$ It is perhaps necessary to note that we are not arguing in terms of Marxian value categories; we do not attempt to compute rates of exploitation, which may well vary across regions, since we do not have regional data on the distribution of income between profit and wages. Thus, regional rates of productivity are strictly in price terms. Nevertheless, this methodology does allow us to explore some of the drivers of absolute and relative surplus value production, namely working hours and labour productivity.
} 
surveys. ${ }^{6}$ Hence, those away from work, through either illness or holiday, are not included. By averaging over the year, i.e., by drawing on data from four surveys, we arrive at the estimate for total hours per worker per week in each region reported in Table 1. Finally, we multiply by 52 and by the average number employed in the year, in order to arrive at total annual hours of labour input for each region. We use this figure in the calculation of hourly labour productivity reported below.

The measure of regional output used is gross domestic product at basic prices, ${ }^{7}$ calculated using the income approach. We use this instead of an expenditure measure because of the greater availability of regional income data for the UK. This approach has the advantage of allowing the GDP estimates to be calculated on a residence basis, achieved by attributing the gross wages and salaries of commuters to the region in which they live, rather than to the region of their workplace. While most people reside in the region in which they work, some do not. ${ }^{8}$

\footnotetext{
${ }^{6}$ The derived variable sumhrs is used in our estimates. We use this measure since we are interested in the total actual labour input of all workers in a region. See Williams (2002) for a discussion of alternative measures of hours worked in the UK.

${ }^{7}$ This measure excludes net taxes on output (e.g. VAT, duty) but includes taxes on production (e.g. business rates). Given the lack of regional price deflators, it is measured in current prices. In line with the definition of the European System of Accounts 1995 (ESA95) from 2002 this measure is referred to as 'gross value added'. The data are taken from Clifton-Fearnside (2001). See also Lacey (2000) on the methodology used in creating the regional accounts.
}

\footnotetext{
${ }^{8}$ That is, our data indicate the output produced by the population of a particular region, regardless of which region it is created in.
} 
Using the residence-based output measure is important for two reasons. First, the Labour Force Survey is a household survey, and the data therefore relate to region of residence. Second, commuter flows into London from its surrounding regions are very large, leading to possible distortions in measures of per capita income. Hence, if these flows are ignored the output of London residents will be overestimated, while the output produced by residents of the surrounding regions will be underestimated. Given that we are interested in the income per head of people living in the particular regions of Great Britain, we must take these flows into account.

\subsection{Classifying Regions}

Since we are offering a regional analysis it is important to reflect on the appropriate level of geographical detail for our study. The Kilbrandon Commission (HMSO, 1973) argued that regions are geographically, administratively and/or historically distinct territories. Hence, we initially focused on the nine Government Office Regions of England, formed in 1994, together with Wales and Scotland, for which regional residence-based estimates of GDP are available. ${ }^{9}$ Although this masks further sub-regional variations, operating at this level has the advantage that the estimates from the Labour Force Survey will be reliable, given the large sample size available for each of these regions. The boundaries of these regions are, in part, arbitrary. Wales and Scotland, of course, have distinctive heritages and historically recognised borders. However, the same may not be said of the nine Government Office Regions of England, the boundaries of which are — socially, culturally and economically —

\footnotetext{
${ }^{9}$ These regions are coincident with NUTS level 1 of the standard European classification system for sub-national statistics. Although these data are available for Northern Ireland, data on commuting times, which we draw upon later on, are not. We therefore do not consider the province in our study.
} 
porous. With this in mind, and with regard to the data on UK regions, we have grouped our regions into four 'meta-regions', viz.: (i) London; (ii) East and the South East; (iii) the rest of England and Wales; and (iv) Scotland.

The region 'London' comprises a greater area than the old County of London, and is identified with the area administered by the Greater London Authority, headed by the elected mayor as strategic head. In this paper the term 'London' will be used to refer to this geographical, administrative and historically distinct territory, which we conceive of as a 'city-region', since this term is 'sufficiently general and descriptive' to capture the different types of interaction between London and its hinterland (Budd, 2006, p.263). The fluidity between London and the regions bordering it raises further questions about whether we should group it with the East and South East. Budd has suggested that 'there are not significant differences between the formal London region and its neighbours’ (2006, p.257). For reasons to be discussed presently we believe that London should be distinguished from the East and South East; however, the latter two regions occupy an intermediate position between London and the rest of the English Government Regions. In particular London represents an important external focal point for the East and the South East, such that we might be better categorising the 'Greater' South East a super-region, or city-region, which has Greater London as its central focus (Gordon, 2003). The precise nature of the labour market in this metaregion also warrants some consideration. While some have suggested linkages and commonalities — for example Gordon et al (2004, p.30) has suggested the 'Greater' 
South East constitutes a single labour market — others have suggested there are marked differences in the labour markets within regions. ${ }^{10}$

Social scientific analysis can be (and is) conducted at a number of different levels. In our analysis we have treated London as a distinct region which nevertheless has strong linkages to the surrounding regions, namely the East and South East. The latter are heavily influenced by their proximity to London, such as through commuter flows. While recognising the porous nature of these boundaries, we nevertheless maintain this framework — which considers London separate from the East and South East — is useful and, in the light of the data, empirically justifiable.

\subsection{Empirical Evidence: A North-South Divide?}

The data used for our regions is collected for 2001, the latest date for which reliable estimates of regional GDP are available. Table 1 reports the actual values of each of the component parts of the decomposition for our four 'meta-regions'. As we might expect, both hourly labour productivity and per capita income are highest in London, followed by East/South East. Turning to consider working hours, differences in average weekly hours are less marked within Great Britain than they are in comparison between countries. However, as will become clear, working hours do play a role in explaining differences in regional per capita income. ${ }^{11}$

\footnotetext{
${ }^{10}$ For example, concerning the East: 'The region is clearly not a single homogenous labour market, but many distinct, overlapping local labour markets that display as many differences as similarities' (Gray et al., 2006, p.194)

${ }^{11}$ Lower intra-national dispersion in hours is to be expected, given greater institutional differences between rather than within countries. Regional differences identified in the UK are more likely to be due to differences in industrial composition, and the extent of part-time working.
} 


\section{TABLE 1 ABOUT HERE}

Regional differences become more apparent in Table 2, where the data are expressed relative to the British average. From these figures it is clear that regional differences in GDP per capita are greater than those in labour productivity (GDP per hour worked). Labour productivity in London is 27 percent above the average, but per capita GDP is 31 percent higher; for the East/South East the figures are 5 and 12 percent, respectively. Conversely, in Wales and the English provinces, while hourly productivity is 8 percent below the national average, per capita incomes are 12 percent below. Thus, differences in labour productivity are insufficient to explain the greater dispersion in per capita outcome, which thus warrants explanation.

\section{TABLE 2 ABOUT HERE}

Having established that GDP per capita is more dispersed than regional variations in labour productivity it is important to try to account for these differences. Our decomposition points to the importance of working hours, unemployment, inactivity and the age profile of the population in explaining these differences. Table 3 outlines the relative effects of each of these variables in explaining the differences between labour productivity and output per head. While variation in working hours is not on the whole large, Londoners' longer working hours do account for 3.6 percentage points of the productivity-per capita GDP differential for that region and Londoners work, on average, 72 minutes longer each week than workers in our 'Rest of England and Wales’ meta region. In fact, London is an interesting case. In the East and South East the effects of working hours, employment rates, and labour-force participation are complementary, combining to increase per capita GDP; in the rest of England and Wales, the same components combine to depress output per head. But in London 
these components have opposite effects. Thus, besides working longer hours when in work, Londoners are more likely to remain economically active beyond usual retirement ages (see Table 1 or 2 ) and are also more likely to be unemployed. Claims for the economic success of London should be tempered in the light of these findings.

\section{TABLE 3 ABOUT HERE}

The fortunes of those resident in the East and the South East are tied to those of Londoners. Many people who live in this 'meta-region' commute into London to work, but these commuters contribute to the marginally superior performance, in terms of hourly labour-productivity, of the East and South East. In terms of per capita GDP, the performance of the East and South East is boosted to a marked 12 per cent above the national average by longer working hours, higher employment, and higher participation in the labour force. Clearly, London provides jobs attractive enough to draw in large numbers of workers willing to endure lengthy commutes, yet the high unemployment rate among Londoners suggests a shortfall in Londoners qualified to fill these jobs.

We should reiterate at this point that we are interested in regional patterns because of an interest in well-being and welfare. Even though a key driver of this is productivity, regional productivity is not generally of interest to prospective employers in a region. They are interested in the particulars of location costs and potential subsidies, and the costs and skills of the workforce as they affect them. They are concerned with firmspecific costs and productivity, rather than the general pattern in the region in which they actually or potentially operate. Hence interest in regional productivity, including that of government, must be more from the perspective of regional policy (concerning 
the well-being of residents) rather than from the perspective of industry. Yet despite this clear motivation for a perspective broader than the solely neoliberal one, we find most evaluations of regions' success focus upon commodity-orientated measures. Acknowledging this has clear implications when we evaluate how meaningful GDP per capita and regional productivity measures are respectively.

It has been maintained here that serious adverse factors counteracting the perceived benefits accruing from high levels of GDP per capita must be recognised. High productivity, which seems to be universally interpreted as beneficial by policymakers, can be set in the context of intensive working, unacceptable working practices and a lack of autonomy over the pace and regularity of work. High unemployment seems to indicate a poor distribution of work and, as a consequence, a poor distribution of income (as argued by Gorz, 1994). Long working hours may reflect reduced underemployment vis-à-vis the rest of Great Britain, but we believe long hours are more likely to be a result of the power of employers and cultural norms which have a regional/spatial dimension (Philp et al, 2005). Finally, while some Londoners may be working beyond retirement age because they enjoy such (poietic) activity we suspect the majority do so because they are poor and have no effective choice. $^{12}$

\footnotetext{
${ }^{12}$ Data from the Department for Work and Pensions' Households Below Average Income survey show that London suffers from the highest incidence of pensioners (over 20\%) on low income among UK regions (New Policy Institute, 2007, graph 6).
} 


\section{Productivity, social productivity and commuting}

In the previous section we reported that higher per capita incomes in the East, South East and London are driven by a number of factors. Most important of these is greater hourly labour productivity and, in London, longer working hours. Conventionally, measures of productivity only take into account time actually spent at work (that is, at the workplace) and, indeed, this is the appropriate measure from the perspective of private employers. However, many employees may consider the working day to begin when they begin to prepare for work and end when their time once more becomes their own. The working day may be even longer when one takes into account other work-related activity, such as personal grooming activities, periods of work-related thought at home, and numerous other possible additional activities. In other words, the home-work interface is blurred, as much activity undertaken outside formal work time could be considered a necessary part of work. ${ }^{13}$ Perhaps the most significant and measurable of these is commuting.

In this section we shall consider this general theme, exploring commuting times for our meta-regions, using the Department for Transport's National Travel Survey (NTS). We will, in particular, consider the role of commuting in relation to London and its neighbouring regions, before defining and calculating our measure social productivity, which endogenously incorporates time forgone commuting.

We have chosen to look at commuting times, rather than distances, for a number of reasons. First, epistemologically, time is a unifying element in examining work,

\footnotetext{
${ }^{13}$ This blurring of the work-life boundary has been discussed by a number of authors. See, inter alia, Hardt and Negri (2000) and Mitchell, et al (2003).
} 
commuting and caring. In considering productivity, in its broadest sense, it makes theoretical sense to talk in terms of commuting time. Secondly, empirical research suggests that people are concerned with the duration of their journey to work, or ‘commuting tolerance’ (Clarke et al, 2003, p.200). In investigating this Pooley and Turnbull (1999) suggest that, for the UK, the average commuting distance increased significantly during the twentieth century, while journey times remained roughly the same. Thus, 'most people appear to have a threshold of time up until which they are prepared to travel ... [and] the distance travelled in this time has increased as transport modes have changed and people have gained access to faster forms of transport' (Pooley and Turnbull, 1999, p.285). ${ }^{14}$ The pattern of recent decades suggests a trend of increasing commuting times with greater variation between people (Bannister and Gallent, 1998). However, such a national average may be misleading since in the 1990s they were almost exclusively generated by longer commutes in the South East and London (Oswald and Benito, 2000).

In order to investigate the commute we obtained data from the Department for Transport's National Travel Survey (NTS). Following ad hoc surveys since the 1960s, the survey has been running continuously since 1988. It is based on detailed sevenday individual travel diaries (as well as some follow-up face-to-face interviews) in which respondents report trip purpose, method of travel, duration of trip and time of day; respondents also provide demographic information, such as age, sex, working status and so on. During the period of interest to us here, approximate annual sample numbers were 3000 households and 7000-8000 individuals. This particular source of

\footnotetext{
${ }^{14}$ The Census H-SAR does provide information on commuting for a significantly higher sample size, approximately $1 \%$ of the UK population. However, since respondents are asked the distance of their home to work travel, this study is not suitable for our purposes.
} 
data is appropriate for our purposes for several reasons. First, since it is diary-based and, moreover, a dedicated travel survey, we can expect a greater degree of accuracy. Certainly we would expect recorded commuting times to be closer to time actually spent commuting than those in response to a question that asks respondents to recall their 'usual' commuting time. Second, and related to the first point, it allows us to take account of persons in employment whose commuting time for the week is zero, or lower than 'usual', due to sickness, holiday absence or home-working. This is important. The annual commuting time of a worker who works from home one day in ten is 10 percent lower than a figure calculated on the basis of their 'usual' commute would suggest. Finally, sampling takes place throughout the year and thus will not be biased by such factors as school holidays. The NTS does suffer from one weakness, however, and this is its relatively small sample size. To overcome the problems of 'noisy' data — because of the small sample size — we pool values for the three years 1999-2001. Preliminary analysis suggests that this pooling is justified, since for no region is there a significant — either statistically or economically/socially — time trend in commuting times over this period; in fact, this follows DfT/ONS practice in reported data pooled over three years. ${ }^{15}$

Using this data mean commuting times are calculated and reported in Table 4, whilst modified working hours are depicted in figure 1 . What is striking about the data is the long commutes endured by Londoners: on average more than three-and-a-half hours per week, 50 minutes per week longer than the next highest meta-region, East and South-East, and 80 minutes longer than the rest of England and Wales. It should be emphasised again that actual weekly commuting times are far higher than this, since

\footnotetext{
${ }^{15}$ From 2002, the NTS sample size has almost trebled, which will allow single-year reporting and analysis of results.
} 
these weekly averages are calculated on the basis of total annual commutes. There will also be dispersion since these are mean figures, hence some will be commuting well above the benchmark 'tolerance zone' of 30-45 minutes per journey suggested by Clarke et al (2003, p.200). ${ }^{16}$ Overall, our data suggests that Londoners commute an average of 43 hours a year longer than their near neighbours and 69 hours a year longer than other residents in England and Wales. This is in addition to the fact that they already spend longer at the workplace. We maintain this should be taken account of in assessing the average welfare of people resident in those regions.

\section{TABLE 4 ABOUT HERE}

The causes and effects of these longer commuting times for London and the Greater South East have been subject to discussion. If workers in London are working 50 minutes more per week than those in the East and South-East, and 80 minutes longer than the rest of England and Wales, is this problematic? Green et al (1999) acknowledge that while many workers are reluctant to endure long commutes, they often see no alternative to this in preserving their standard of living. Indeed, Frey and Stutzer (2004) cast outcomes in an even more negative light, arguing that those who spend more time commuting report a lower level of 'life' satisfaction, as they do not generally feel that they are being compensated sufficiently - in terms of higher salary, lower rent costs or better environment - for the burden of commuting. ${ }^{17}$

\footnotetext{
${ }^{16}$ Research by Doyle and Nathan (2001, p.4) has suggested that there are important occupational differences in commuting times. Those in managerial and professional occupations travel for approximately twice as long as manual workers.

${ }^{17}$ O’Connor (1973) traces the process by which suburbs developed historically, and suggested that as cities developed they 'became a wasteland' which 'commercial property owners and businessmen,
} 


\section{FIGURE 1 ABOUT HERE}

Commuting is also especially important in considering the relationship between the different regions in the 'Greater' South East. As noted by Budd, the lives of those living in the South East and the East are, as a consequence of the high volume of commuting, 'heavily determined’ by London (2006, p.252). Employees in London and the South East experience longer commutes, no doubt in part because of the pressures of the housing market in those regions, and difficulties people experience in finding affordable housing near to their workplace (Oswald and Benito, 2000).

If we recognising these (time) costs for employees, it becomes important to seek to endogenise them in our analysis of economic welfare indicators; it is important to try to incorporate some understanding of additional time involved in work-related activity in our assessment of regional well-being. While it is difficult to quantify and separate all work from household activity, one significant work-related activity, commuting, can be subjected to empirical investigation. And, by looking at time use, national and regional transport policy can thus be connected to broad questions of living standards

independent professionals, and the new corporate retinue' could not control (1973, pp.125-6). Hence there emerged a suburban elite who could get more space and control their environment away from the city. Those that were particularly rich could create viable enclaves in the city, but these were exceptions in the trend where the wealthy - the ruling, middle and better-off working class - deserted the city. The wages generated and kept in the city were low, while salaries and profits which flow to the suburbs are correspondingly high. We are not denying that many people commute because a more pleasant environment can be enjoyed at a cost they can afford. What we are arguing is that it is important to note that the time cost of this choice - the commute - needs to be endogenised in analysing the well-being of these people. 
and well-being. Given this data, it becomes possible to identify average income levels, and to calculate their ratio to average time foregone in work and work-related activity. Quite apart from the monetary, environmental, and other costs associated with commuting, we argue this is an appropriate 'social' measure of productivity, to be used to assess regional well-being. This measure, social productivity, can be distinguished from the conventionally-defined productivity measure, which is business-orientated and externalises the environmental and human costs associated with commuting.

To elaborate formally, let us now measure social productivity for the meta-regions identified previously. We define social productivity in region $i$, to be,

(5) $y_{i}^{\prime}=\frac{Y_{i}}{H_{i}+C_{i}}$,

where, $Y_{i}$ and $H_{i}$ are respectively total output and total number of paid-for hours worked, ${ }^{18}$ as above, and $C_{i}$ is total number of hours spent travelling to and from work. Note that we can rewrite (5) in terms of mean values:

(5a) $y_{i}^{\prime}=\frac{y_{i} h_{i}}{h_{i}+c_{i}}$,

where, $y_{i}$ is average hourly labour productivity, $h_{i}$ is average weekly working hours, and $c_{i}$ is average weekly commuting time (all for persons in employment). ${ }^{19}$

\footnotetext{
${ }^{18}$ We count as paid-for hours all time spent at work, regardless of LFS classification ('paid' or 'unpaid' overtime, etc.).
} 
Using our data, we can re-calculate productivity figures to obtain a measure of 'social productivity', which includes commuting time. This figure is sensitive to changes in commuting times and more completely captures the experience of people resident in the regions under investigation. This measure of 'social' productivity is shown with 'private' productivity in figure 2. In looking at private and social productivity note that private productivity is $£ 2.20$ per hour higher in London than is social productivity. In Great Britain as a whole productivity is $£ 1.40$ per hour higher than social productivity. As a consequence private productivity is 10.7 per cent higher than social productivity in London as opposed to 8.5 per cent in Great Britain as a whole. ${ }^{20}$

\section{FIGURE 2 ABOUT HERE}

The regional differences identified in this section are not large; however, the cumulative effects of long working hours, higher work intensity, working until older, increased likelihood of unemployment, and longer commutes are likely to undermine well-being in those regions where these conditions are most adverse. In this section we have identified a major time-cost directly attributable to productive activity in GB regions. We have shown that this cost is by no means uniform across GB, and that those in London, in particular, are likely to experience a higher incidence of long-

\footnotetext{
${ }^{19}$ We have (dropping subscripts for simplicity), $y=Y / H, h=H /(52 E)$ and can define $c=C /(52 E)$. Then $y^{\prime}=\frac{Y}{H+C}=\frac{y H}{H+C}=\frac{52 y h E}{52 h E+52 c E}=\frac{y h}{h+c}$.

${ }^{20}$ There are complicating factors in measuring productivity. There has been discussion about the effect on productivity, of longer working hours. So, too, longer home-to-work journey times may also impact adversely on productivity (see Schubert et al, 1987, pp.76-78; Rice et al, 2006).
} 
commutes (in terms of duration of time). In this sense claims for the economic success of London should be tempered in this light.

\section{Conclusion}

This paper has argued that there are regional differences in GDP per capita, productivity, and social productivity. It is suggested that conventional measures of regional well-being, such as GDP per capita and productivity measures, may mask or not take account of other important considerations, such as variations in the length of the working day, labour market, and demographic factors. In our study we show how these are important when considering the success of London, in relation to the rest of Great Britain. We demonstrate that Londoners on average work longer, are more likely to work beyond retirement ages and are more likely to be unemployed than their British counterparts.

There are other important considerations when we reflect on the regional data produced for 2001. In particular, we consider the underlying purpose of government measures such as regional GDP per capita. It is apparent to us that the purpose of these measures is to consider relative economic welfare levels in different parts of the country. It cannot be to inform industry, since firms are interested in their particular circumstances rather than regional or geographical patterns. If it is the case that this data is to be used to inform policy we suggest a method by which labour market and demographic factors can be incorporated into the analysis and, further, show that 'time foregone to work' is a more meaningful approach in looking at relative welfare levels than the more orthodox — employer orientated — measures of hours worked. 
Our measure — of 'social productivity' — is especially useful in that it offers a measure which incorporates output and a richer notion of time use. This measure is of use to policymakers who are genuinely interested in issues of work-life balance, time use, and potentially it will allow better understanding of well-being and transport policy in London, other parts of the 'Greater' south east, the rest of England and Wales, and Scotland. On this basis we propose this new measure as one that can be used alongside more conventional measures. 


\section{References}

Bannister, C. and Gallent, N. (1998) Trends in commuting in England and Wales becoming less sustainable? Area 30(4), pp.331-42.

Benneworth, P., Hardill, I., Baker, M., and Budd, L. (2006) ‘Introduction’, in Hardill, I., Benneworth, P., Baker, M. and Budd, L. (eds.), The Rise of the English Regions? London, Routledge, pp.3-21.

Budd, L. 2006. 'London’, in Hardill, I., Benneworth, P., Baker, M. and Budd, L. (eds.), The Rise of the English Regions? London, Routledge, pp.245-266.

Clarke, M. and Islam, S.M.N. (2003) 'Measuring social welfare: application of social choice theory', Journal of Socio-Economics, 32, pp. 1-15.

Clark, W., Huang, Y. and Withers, S. (2003) Does commuting distance matter? Commuting tolerance and residential change. Regional Science and Urban Economics, 33, pp.19921.

Clifton-Fearnside, A. (2001) 'Regional accounts 1999: part 1, regional gross domestic product', Economic Trends, no. 568, March.

Crafts, N. (1997) Economic Growth in East Asian and Western Europe Since 1950: Implications for Living Standards. National Institute Economic Review, 162, pp. 7584.

Doyle, J. and Nathan, M., (2001) Wherever Next: Work in a Mobile World. London: The Industrial Society. 
Frey, B. and Stutzer, A. (2004) Economic consequences of mispredicting utility. Institute for Empirical Research in Economics, University of Zurich Working Papers Series 218.

Gray, M., Martin, R., and Tyler, P. (2006) 'The East', in Hardill, I., Benneworth, P., Baker, M. and Budd, L. (eds.), The Rise of the English Regions? London, Routledge, pp.184203.

Green, A., Hogarth, T. and Shackleton, R. (1999) Longer distance commuting as a substitute for migration in Britain: A review of trends, issues and implications. International Journal of Population Geography, 5, pp.49-67.

Gordon, I. (2003) 'Three into one: joining up the Greater South East', Town and Country Planning 72, 11, pp.342-343.

Gordon, I., Travers, T., and Whitehead, C. (2004) London's Place in the UK Economy 2004. London: London School of Economics for the Corporation of London.

Gorz, A. (1994) Capitalism, Socialism, Ecology. London: Verso.

Hardt, M. and Negri, A. (2000) Empire. Cambridge, MA: Harvard University Press.

Harvey, D. 1985. ‘The Geopolitics of Capitalism’, in Gregory, D., and Urry, J. (eds.), Social Relations and Spatial Structures. London, Macmillan.

HMSO. 1973. Royal Commission on the Constitution (Kilbrandon Commission). Cmnd 5460-1. London: HMSO.

Kluger, A. (1998) Commute variability and strain. Journal of Organizational Behavior, 19, pp.147-165. 
Lacey, D. (2000) 'UK regional gross domestic product (GDP): Methodological guide’, Economic Trends, no.565, December.

Maddison, A. (1995) Monitoring the World Economy, 1820-1992. Paris: OECD.

Marx, K. (1976) Capital: A Critique of Political Economy, Volume I. London: Penguin Books.

Martin, R. (1998) ‘Regional Dimensions of Europe’s Unemployment Crisis’. In Lawless, P., Martin, R., and Hardy, S. (eds.) Unemployment and Social Exclusion. London: Regional Studies Association.

Mitchell, K., Marston, S.A. and Katz, C. (2003) ‘Life’s Work: An Introduction, Review and Critique'. Antipode, 35(3), pp.415-442.

Modigliani, F., Fitoussi, J-P., Moro, B., Snower, D., Solow, R., Steinherr, A., and Sylos Labini, P. (1998) ‘An Economists’ Manifesto on Unemployment in the European Union’. Banco Nazionale Del Lavoro Quarterly Review 206, pp.327-361.

Negri, A. (1994) Oltre la legge di valore, DeriveApprodi, 5-6 (Winter).

New Policy Institute (2007) ‘Older people in low income’ The Poverty Site www.poverty.org.uk/38/index.shtml (accessed 3/08/07)

O’Connor, J. 1973. The Fiscal Crisis of the State. New York: St Martin’s Press.

Osberg, L. and Sharpe, A. (2005) 'How should we measure the 'economic' aspects of wellbeing?', Review of Income and Wealth, 51(2), pp. 311-336.

Oswald, A. and Benito, A. (2000) Commuting in Great Britain in the 1990s. Warwick Economics Research Papers Series 560. 
Philp, B., Harvie, D., and Slater, G. (2005) 'Preferences, Power and the Determination of Working Hours', Journal of Economic Issues 39(1), pp.75-90.

Pooley, C. G., Turnbull, J., 1999. 'The journey to work: a century of change’. Area, 31(3), pp.281-292.

Rice, P. Venables, A. and Patacchini, E. (2006). Spatial Determinants of Productivity: Analysis for the Regions of Great Britain. Regional Science and Urban Economics, 36, 727-752

Schubert, U., Gerking, S., Isserman, A. and Taylor, C. (1987). Regional Labour Market Modelling: A State of the art review. In Fischer and Nijkamp (eds), Regional Labour Markets. Elsevier Science Publishers.

Smith, A. (1970) The Wealth of Nations, Books I-III, Harmondsworth: Penguin.

Treasury (2001) Productivity in the UK: The Regional Dimension, London: HM Treasury.

van Ark, B. and McGuckin, R. (1999) 'International comparisons of labor productivity and per capita income’, Monthly Labor Review, July, pp.33-41.

Williams, R. (2002) 'Hours worked: a comparison of estimates from the Labour Force and New Earnings Survey’, Labour Market Trends, 110 (8), pp.429-442.

\section{Word count: 7193 (excluding references and tables)}


Figure 1. Commuting time and 'at work' time, 1999-2001

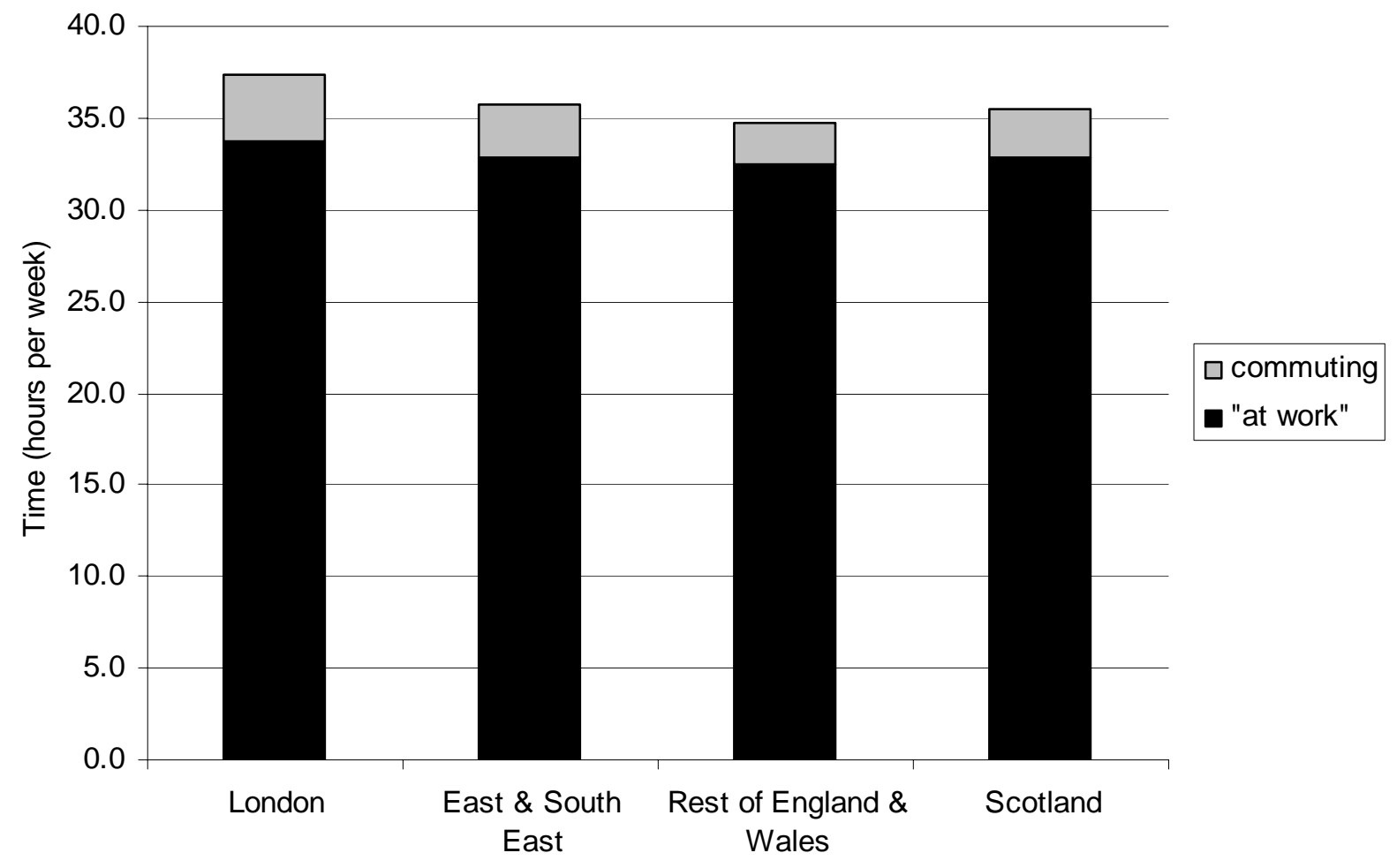


Figure 2. Hourly labour productivity, 'private' and 'social', 1999-2001

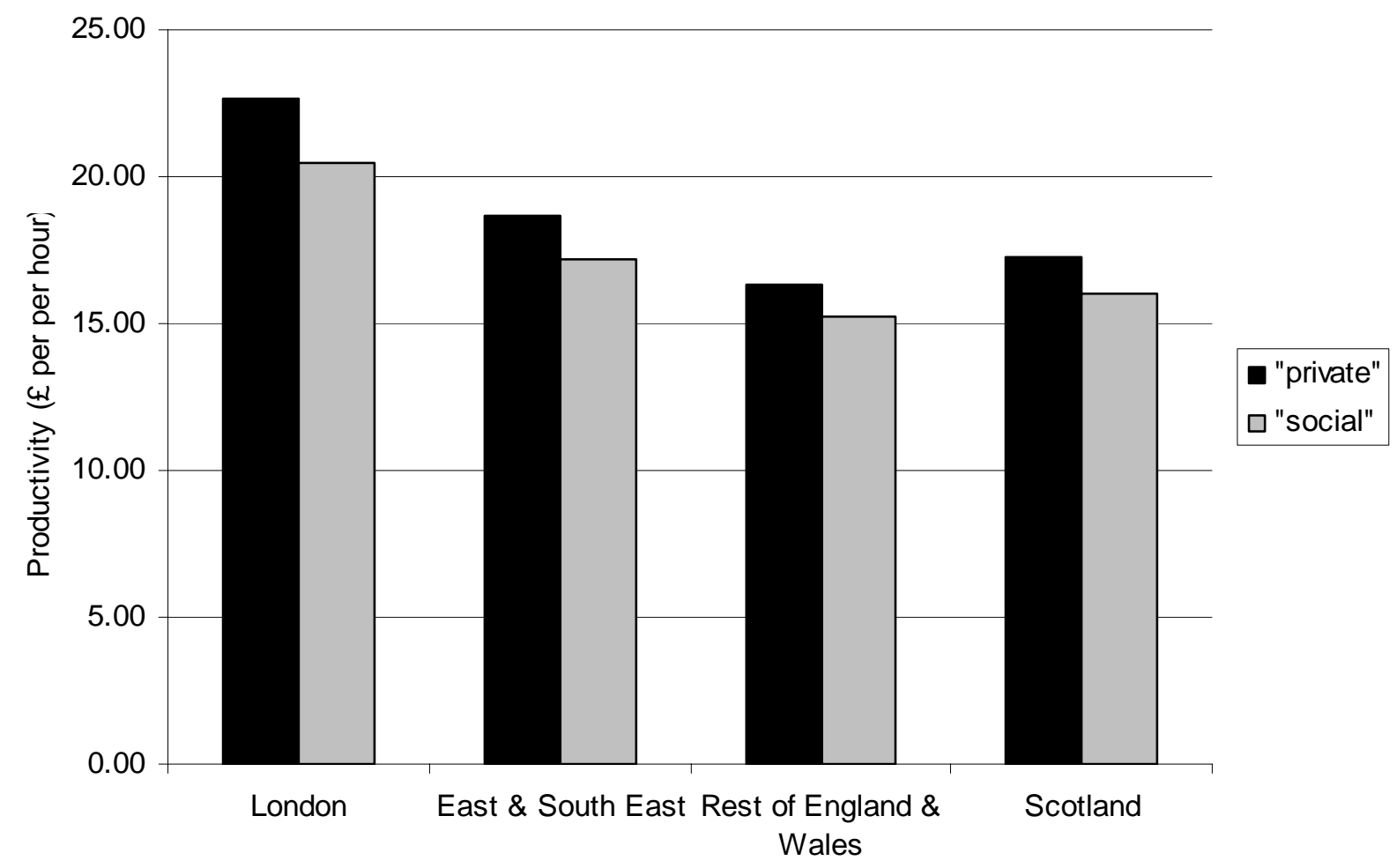


Table 1. Per capita output and component parts, 2001

\begin{tabular}{|c|c|c|c|c|c|c|c|c|c|c|c|c|}
\hline & \multirow{2}{*}{$\begin{array}{l}\text { Productivity: } \\
\text { GDP per hour } \\
\text { worked, } y(£)\end{array}$} & \multirow{2}{*}{$\begin{array}{l}\text { Average } \\
\text { weekly } \\
\text { working } \\
\text { hours, } h\end{array}$} & \multicolumn{3}{|c|}{ Employment proportion, $e$} & \multicolumn{3}{|c|}{ Participation rate, $p$} & \multicolumn{3}{|c|}{ Share of total population, $d$} & \multirow{2}{*}{$\begin{array}{l}\text { Per capita } \\
\text { GDP, Y/P } \\
\text { ( } £ \text { thousand) }\end{array}$} \\
\hline & & & $16-69$ & $9 / 65+$ & All & $16-69 /$ & $59 / 65+$ & All & $16-69 /$ & $59 / 65+$ & All & \\
\hline London & 22.69 & 33.7 & 93.0 & 97.9 & 93.2 & 76.5 & 10.4 & 65.0 & 65.7 & 13.9 & 79.6 & 19.18 \\
\hline East \& South East & 18.68 & 32.9 & 96.4 & 98.0 & 96.4 & 82.9 & 10.8 & 66.7 & 61.9 & 18.0 & 79.9 & 16.43 \\
\hline Rest of England \& Wales & 16.34 & 32.5 & 94.5 & 98.1 & 94.6 & 77.9 & 7.3 & 61.8 & 61.6 & 18.2 & 79.8 & 12.87 \\
\hline Scotland & 17.29 & 32.9 & 93.2 & 99.0 & 93.3 & 78.7 & 6.5 & 63.0 & 63.0 & 17.4 & 80.5 & 14.00 \\
\hline GB & 17.85 & 32.8 & 94.7 & 98.1 & 94.8 & 79.0 & 8.4 & 63.5 & 62.3 & 17.5 & 79.9 & 14.62 \\
\hline
\end{tabular}


Table 2. Per capita output and component parts as percentages of GB average, 2001

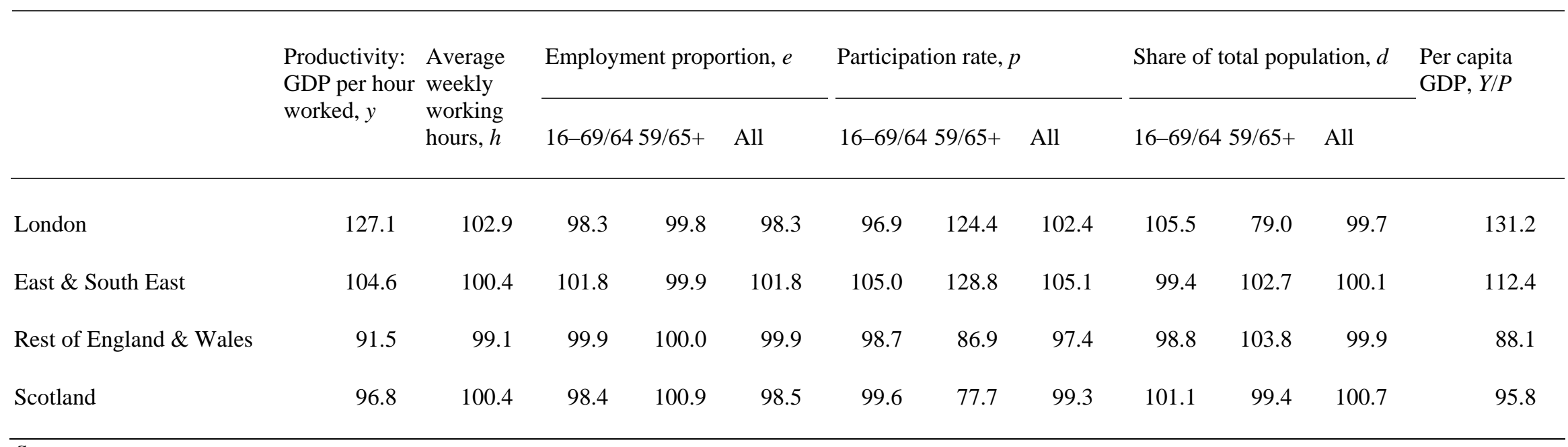

Sources: see text 
Table 3. Decomposition of per capita GDP relative to the GB average into effects of hourly productivity, working hours, employment proportion, labour-force participation and population demographics, 2001.

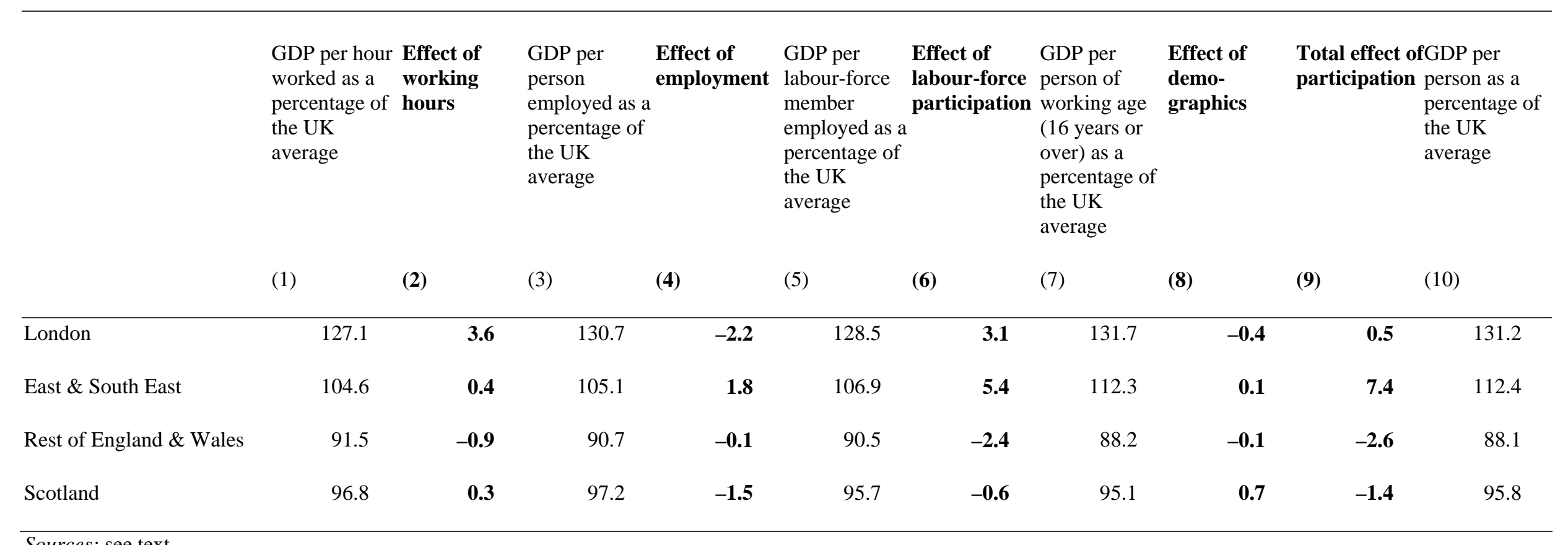

Sources: see text

Notes: columns are defined thus: $(2)=(3)-(1) ;(4)=(5)-(3) ;(6)=(7)-(5) ;(8)=(10)-(7) ;(9)=(4)+(6)+(8)=(10)-(3)$ 
Table 4. Time use and productivity, all employed people, 1999-2001

Time, mean minutes per week

Total work time, Of which, 'at work' + commuting commuting
Productivity, £/hour

'Private’ 'Social’
20.5

London

2,242

219

22.7

17.2

East \& South East

2,144

169

18.7

15.3

Rest of England \& Wales

2,088

139

16.3

17.3

16.0

2,130

156

157

17.9

16.5

Sources: see text 